have been observed to give measurable displacements confirm the earlier results, and seem to place beyond reasonable doubt the conclusion that the sun behaves approximately as a uniformly magnetised sphere, with a polarity corresponding with that of the earth. The deduced values of the field-strength in Gaussian units at the sun's magnetic pole range from 9.9 to 54.7 , but it is shown that, in general, the values corresponding with a given line-intensity are approximately equal. For iron and chromium, at least, there is a rapid decrease in field-strength with increasing lineintensity, and, in view of Mr. St. John's conclusion that lines of increasing intensity represent successively higher levels in the solar atmosphere, it would appear that the strength of the sun's general field falls off rapidly with increasing elevation above the surface. The part of the field at present accessible to observation lies within the bounding surfaces of a thin shell in the solar atmosphere about $150 \mathrm{~km}$. in thickness. The anomalous behaviour of certain lines which fail to show displacements has net yet been completely explained, but the lines in question may possibly originate outside the effective field.

The Spectroscopic Binary Boss I082.-This star, of magnitude 5.3 and type $\mathrm{G}_{5}$, was found to have a variable velocity by the observers at Mount Wilson. The orbit has now been computed by $\mathrm{Mr}$. J. B. Cannon from forty-two photographs of the spectrum taken at the Dominion Observatory, Ottawa, during the years 1916 , I9I 7 , and I9I8 (Journ. R.A.S. Canada, vol. xii., p. 210). The elements of the orbit, with their probable errors, are as follows:--

$$
\begin{aligned}
& \mathrm{P}=\mathrm{I} 2 \mathrm{I} \text { days } \\
& \mathrm{K}=28.19 \mathrm{~km}, \quad \pm 1 \cdot 2 \mathrm{~km} . \\
& e=0.019 \quad \pm 0.042 \\
& \omega=285^{\circ} \quad \pm 42^{\circ} 68^{\mathrm{c}} \\
& \gamma=-40.47 \mathrm{~km} . \pm 0.8 \mathrm{I} \mathrm{km} . \\
& \mathrm{T}=\mathrm{J} . \mathrm{D} .2,42 \mathrm{I}, \mathrm{I} 37.55 \pm 14.26 \text { days } \\
& a \sin i=46,900,000 \mathrm{~km} . \\
& m_{1}^{3} \sin ^{3} i=0.28 \times \operatorname{sun} \\
& \left(m_{1}+m\right)^{2}=0.28
\end{aligned}
$$

\section{MARINE BIOLOGY IN THE UNITED} STATES.

UNDER the direction of Dr. A. G. Mayer, the Department of Marine Biology of the Carnegie Institution of Washington continues to carry out researches of great value, and vol. xii. of the Papers from the department, issued March, I9I8, fully maintains the high standard of previous volumes. From the point of view of general interest, perhaps the most striking paper is Mr. E. W. Gudger's account of the habits of the gaff-topsail catfish (Felichthys felis), a large catfish which is found at Beaufort, North Carolina. In this species the ova, which are very large, being as much as $I$ in. in diameter, are carried in the mouth of the male parent until the larvæ are hatched, and the young are retained in this situation for some considerable time until the yolk-sac has been absorbed. The largest number of eggs found in the mouth of any one male was fifty-five, and numbers above twenty were quite frequent. The habit of oral gestation in catfishes of various species and from many different geographical regions has, of course, long been known, but the carefully ascertained details recorded in the present paper will be much appreciated by field naturalists.

Mr. Gudger also contributes a memoir on the Barracuda (Sphyraena barracuda), a well-known West Indian fish of fierce and voracious habits, which is much used as a food-fish. In the course of this memoir considerable space is devoted to a discussion of the occasionally poisonous character of this fish. As is well known to West Indian residents, although the flesh is generally a perfectly wholesome article of diet, occasional specimens are met with which when eaten cause serious illness, with symptoms which are considered distinct from those of ptomaine poisoning. Although the author has been at some pains to collect all the literature dealing with this poisoning, he has failed to find any modern scientitic account by a medical writer, and it would appear to be a matter which calls for a thorough investigation by those interested in tropical disease. The fact of the occurrence of these cases has been quite familiar to medical practitioners in the West Indies for many years, but, judging from the information in the present memoir, little progress has been made in discovering the cause of the trouble.

Another paper dealing with fishes is one by $\mathrm{Mr}$. C. F. Silvester on fishes new to the 'fauna of Porto Rico. As a result of a three weeks' visit to the island the author obtained eight species which he regards as new to science, and the present communication is devoted largely to a detailed description of these, illustrated by excellently coloured figures.

Miss E. G. White deals with the origin of the electric organs in Astroscopus guttatus, and gives a valuable survey, with a very complete bibliography, of the whole question of the electric organs of fishes, which should be very useful to anyone seeking information on this subject.

Dr. Mayer himself contributes two short papers of considerable importance. The first describes a series of experiments on toxic effects due to high temperature, in which a number of reef-corals were kept in warm ocean-water for sixty minutes in the dark, and the temperature was found which was just sufficient to kill the coral. The author concludes that "it seems possible that death from high temperature may be due to the accumulation of acid (possibly $\mathrm{H}_{2} \mathrm{CO}_{3}$ ) in the tissues, the rate of formation of this acid being related to the rate of metabolism of the tissues. Thus animals of the same class having a high rate of metabolism, as measured by oxygen consumption, are more sensitive to heat and to $\mathrm{CO}_{2}$ than those having a low rate of metabolism." Dr. Mayer's second paper is a short note, in continuation of previous work, on nerveconduction in diluted and in concentrated sea-water, the Scyphomedusa (Cassiopea xamachana) being the animal used in the experiments, and the salinities employed ranging from $18 \cdot{ }^{3} 3$ to 60.96 per thousand.

Mr. J. F. McClendon writes an important paper on "Changes in the Sea and their Relation to Organisms." Adopting the most refined modern methods of analysis, he has studied a number of physical and chemical problems which have a direct bearing on the life of the plants and animals of the sea. Amongst the problems dealt with are ocean currents, oxygen tension in sea-water, and the chemical precipitation of calcium carbonate in sea-water, his observations on the last-named being particularly suggestive.

Mention must also be made of Mr. S. C. Ball's observations on the migration of insects to the Rebecca Shoal light-station, an isolated station ro5 miles from the mainland of Florida and 95 miles from the coast of Cuba. Mosquitoes and house-flies are the insects chiefly discussed, and some striking figures are given which have an important bearing on the problem of insect migration. Other papers are on amphibians and reptiles from Porto Rico and the Virgin Islands by H. W. Fowler, and on the botanical ecology of the dry Tortugas by H. H. M. Bowman. Dr. Mayer is to be congratulated upon a most interesting and important volume.
E. J. A.

NO. 2544 VOL. IOI] 